\title{
CORRECTION
}

\section{Correction: Uncertainty analysis of species distribution models}

\author{
Xi Chen, Lauren A. Castro, Nedialko B. Dimitrov, Lauren Ancel Meyers
}

Dr. Lauren A. Castro should be included in the author byline. They should be listed as the second author, and their affiliation is 2 Department of Integrative Biology, The University of Texas at Austin, Austin, TX, USA. The contributions of this author are as follows: Data curation. The correct citation is: Chen X, Castro LA, Dimitrov NB, Meyers LA (2019) Uncertainty analysis of species distribution models. PLoS ONE 14(5): e0214190. https://doi.org/10.1371/ journal.pone.0214190

\section{Reference}

1. Chen X, Dimitrov NB, Meyers LA (2019) Uncertainty analysis of species distribution models. PLoS ONE 14(5): e0214190. https://doi.org/10.1371/journal.pone.0214190 PMID: 31120909

\section{f OPEN ACCESS}

Citation: Chen X, Castro LA, Dimitrov NB, Meyers LA (2019) Correction: Uncertainty analysis of species distribution models. PLOS ONE 14(12): e0226663. https://doi.org/10.1371/journal. pone. 0226663

Published: December 12, 2019

Copyright: ๑ 2019 Chen et al. This is an open access article distributed under the terms of the Creative Commons Attribution License, which permits unrestricted use, distribution, and reproduction in any medium, provided the original author and source are credited. 